\title{
Manufacturing of solvent-free acrylic pressure- sensitive adhesives in form of self-adhesive layers
}

\author{
Zbigniew Czech*, Dominika Sowa, Paulina Ragańska \\ Institute of Chemical Organic Technology, West Pomeranian University of Technology, Szczecin, \\ K. Pulaskiego 10, 70-322 Szczecin, Poland
}

*E-mail address: psa_czech@wp.pl

\section{ABSTRACT}

The present publication is related to a process for producing the sensitive adhesive (PSA). New applications and technical specificati development of new methods of polymerization of solvent-free acryl . New sy acrylics includes polymerization in the reactor with removal of th
carrier. The polymerization process is connected with UV-crosslit ing.

Keywords: pressure-sensitive adhesive; acrylics; polymeri ation; solvent-free, JV-crosslinking

\section{INTRODUCTION}

Pressure-sensitive adhesives are bein ased 2or various products represented by adhesive tape, labels, protective at corative foils [1]. Their functional characteristics like instantaneous adhesiveness, $r$ ated dhesiver ss, tackiness, etc. as well as their ease of adhesive work, and the ap ican and in various directions. Together with the expanding applications or PSA, capabilities required for PSA also are widening, and various types of PSA a een devely d.

The desire to $\mathrm{PS}$ vithout having to deal with organic solvent has been with us almost as long as self-adhes coducts have been in mass production [2]. The hot-melt types, disper on typ and oth $\mathrm{cr}$ technologies for non-solvent types PSA are being realized for a part of $\mathrm{t}_{\mathrm{L}}$, icatio for PSA. However, technologies for substitute solvent-free types of PSA in sec requing high performance in regard to weather resistance or heat resis ance ve not completed, and acrylic PSA of the solvent type continue to be used wi. $[3,4-17]$.

-min $\sim$ A, however, only achieved real practical significance in the $70 \mathrm{~s}$ with the appearan of thermoplastic rubber, the styrene-butadiene (SBS) and styrene-isoprene (SIS) block copo ymers [4]. These thermally reversible or physically crosslinking products allow the formulation of hot-melt PSA with good processing performance. There is no need here to describe in detail the typical disadvantages such as unacceptable temperature resistance or poor resistance to plasticizers [5].

The ideal would be to link the proven good PSA properties of acrylic PSA produced or formulated in solvents (including water) with solvent-free acrylic adhesive systems. Acrylic pressure-sensitive adhesives which are UV-crosslinked or which are polymerizable on the carrier suggest them here. 
Photoinduced UV-crosslinking is a rapidly expanding technology on PSA area resulting from its main advantages such as solvent-free process, efficient and economical energy used new properties and quality of chemical crosslinking bonding [6-10].

Three different manufacture processes were tested in experiment like polymerization in the extruder with subsequent UV-crosslinkink, polymerization in the reactor with removal of the solvent and UV-crosslinking of the solvent-free PSA or polymerization of syrup-type PSA directly on the carrier.

The first development work on using the extruder as the chemical reactor for polymerization was carried out some 60 years ago. A patent publication [11] describes a continuous process for the polymerization of acrylate monomers in a single or do extruder. A degree of transformation of 93 to $99 \%$ is achieved by suitable so ew geom and adjusting the temperature of the various zones of the extruder. The a ple give however, does not cover a pressure-sensitive adhesive, the glass transition apera $\left(\mathrm{T}_{\mathrm{g}}\right)$ of the extrusion polymerizate being approximately $29^{\circ} \mathrm{C}$.

European patent [12] describes continuous radical polymeriza in spec 1 inactor. An isooctyl acrylate/acrylic acid combination is mentioned in an do ption $\mathrm{dd}$ in the examples.

\section{EXPERIMENTAL}

The following experiments were conducted in der to stud the diverse parameter such as acrylic acid content, radical starter concentration a rew sp ed during the polymerization in the extruder, the viscosity, molecular mack, adhown, cohesion of PSA and on other important properties of polymerization pro ss polymer yield and polymerization conversion.

In the case of polymerizatio he reac or with removal of the solvent the conducted trials have shown comparison vario acrylic Yot-melt PSA, influence on web speed at 40 and $120 \mathrm{~g} / \mathrm{m}^{2}$. The UV-cros $\mathrm{m}$. melt PSA were compared with a conventional acrylic dispersion.

During the polyp ation proc on carrier the conducted experiments have shown the relation between the $\mathrm{VV}$ e $\mathrm{v}$ with arious irradiation strength and the conversion ratio for a fixed added ar wont of pho itiator, the relation between the number of UV irradiation passes and th conve sion ratio ander the various conditions, the web speed vs. coat weight and coating of $\sim \mathrm{V}$-ci sslinked acrylics based on UV polymerizable syrup.

2-Ethylhe acryla 2 , acrylic acid and 2,2'-azo-diisobutyronitrile are available from BASP (c many) unsaturated photoinitiator 4-acryloyloxy benzophenone (ABP) is ay ble f sm Chem rec Company (Germany).

of synthesized in extruder PSA was measured with viscometer RM 180 Rheoma com Rheometric Scientific Company. Their molecular mass was certained with HPLC-Sys $n$ with Isoctratic Pump \& DRI-Detector form HP Company.

Tack, adhesion and cohesion of investigated acrylic pressure-sensitive adhesives were tested according to A.F/E.R.A. 4015 (tack), 4001 (adhesion) and 4012 (cohesion). 


\section{1. Polymerization in the extruder with subsequent UV-crosslinking}

The objective of polymerization in the extruder is to produce solvent-free crosslinkable acrylic PSA, having a conversation rate above $97-98 \mathrm{wt}$ \% with residual monomer content lower than 2-3 wt. \%, characterized by molecular mass $\mathrm{M}_{\mathrm{w}}>250000$ Dalton.

\section{Influence of technical parameters like screw speed}

The experiment was carried out in a double-screw extruder from the Leistritz Company (Nürnberg) with eight heatable zones including a degassing zone, with it being possible to adjust the speed of the screws and the temperatures in the various zones in a wide ranom The polymerization process was carried out with a monomers mixture selected of 0 . .0 pa. ethylhexyl acrylate (2-EHA), 5 parts acrylic acid (AA), 0.5 parts 4-acryloylox enzopheno (ABP) and 0.5 parts of thermical initiator 2,2'-azo-diisobutyronitrile (A $\mathrm{MBN}$ ) the bas recipe.

The variable technical parameters are screw speed and the length the es yder z As was to be anticipated, the polymerization yield and the viscos $\mathrm{V}$ PSA produced declines with increasing screw speed as the reaction time actuall availabi creas os (Fig. 1).

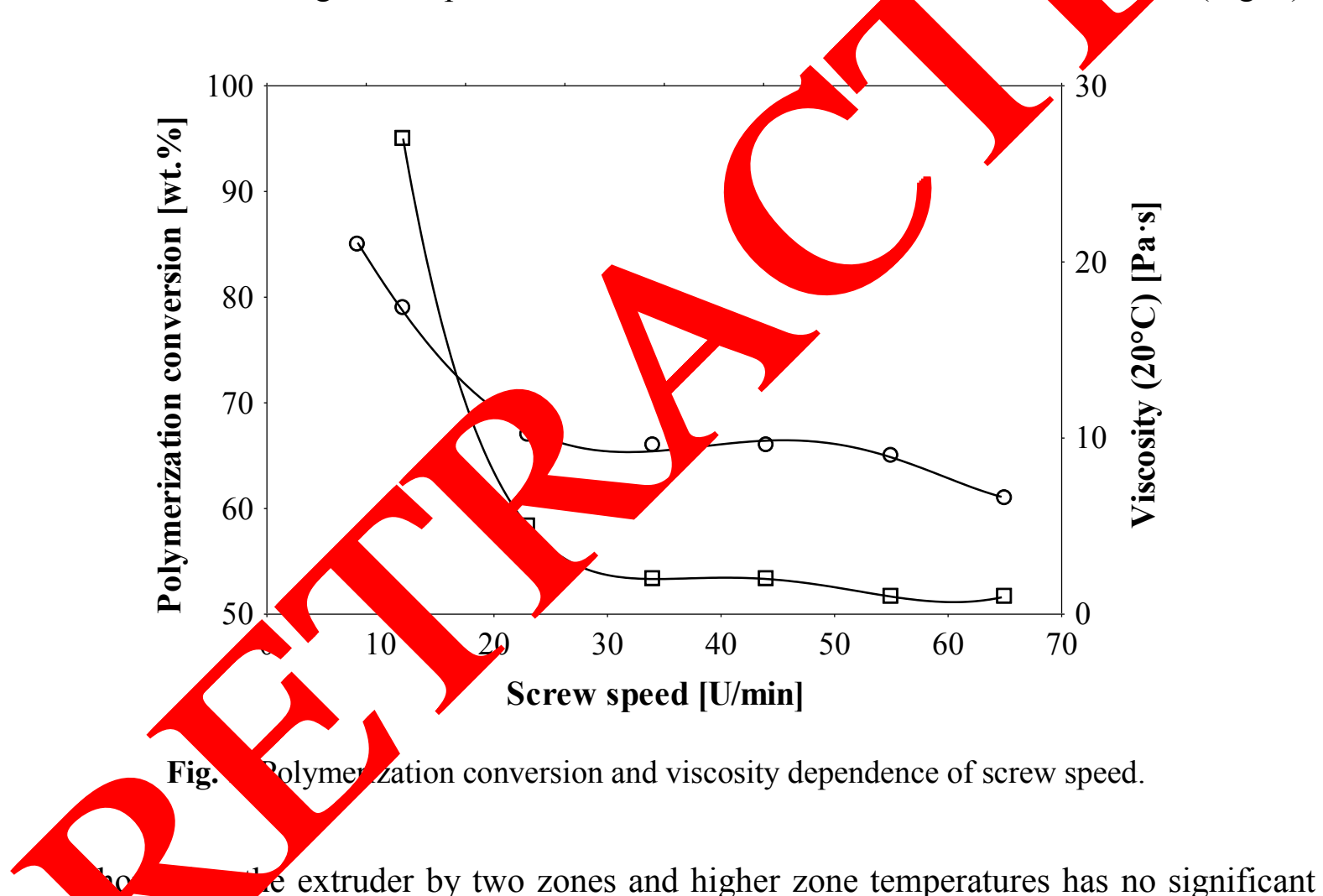
effect $\delta$ polymerization yield. It remained in the range from $70-80 \mathrm{wt}$. $\%$. The best results of the poy. Crization yield and viscosity of PSA were achieved with the screw speed of 5 rpm. The greatest weakness in the system was the degassing zone which did not permit the greatest possible removal of the residual monomers.

\section{Influence of the acrylic acid amount and the starter concentration}

Starting from this basis the acrylic acid content has been varied and so the quantity of starter, with the temperatures of the various zones and the screw speed being set as follows:

- Temperature of zones 1-8: 90/90/90/100/100/110/120/120 ${ }^{\circ} \mathrm{C}$ 
- Screw speed: $\quad 5 \mathrm{rpm}$

The influence of starter AIBN and acrylic acid content on the investigated properties such as polymerization conversion and viscosity are presented in Figs. 2-3.

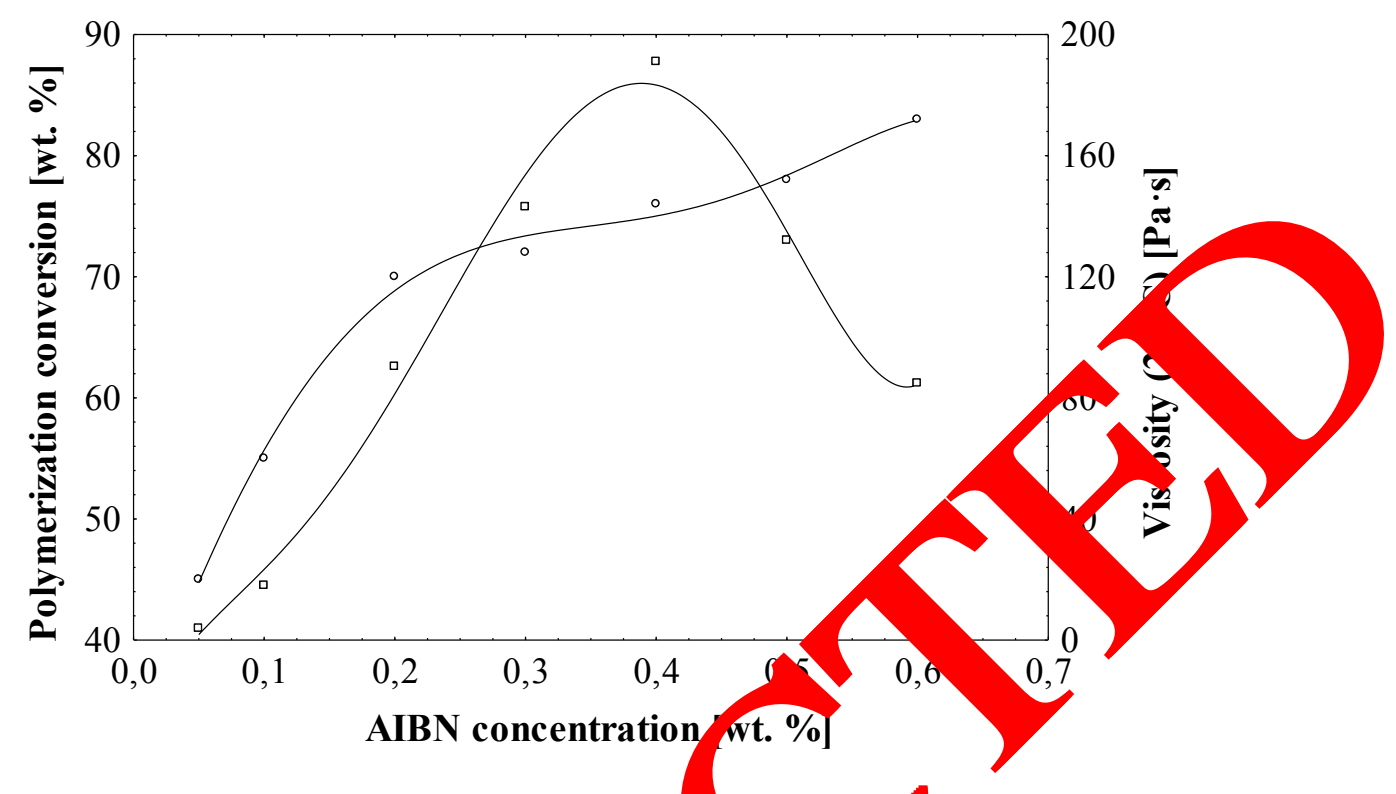

Fig. 2. Effect of AIBN amount on polyn ization yield and viscosity.

As expected, the increase of AIBN affects positively the polymerization conversion. The viscosity shows a maximum roury $4 \mathrm{wt} \%$ of AIBN (Fig. 2).

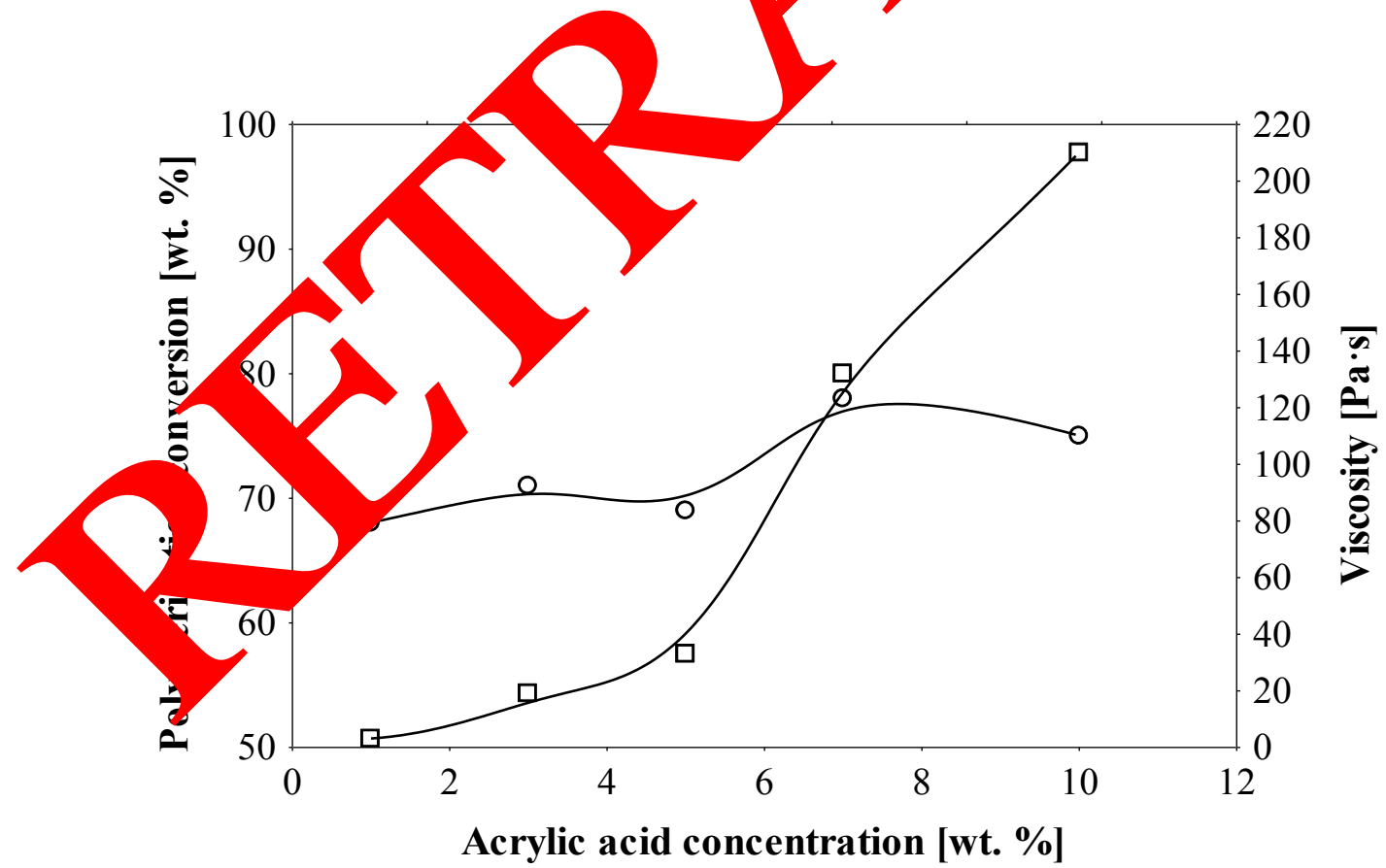

Fig. 3. Effect of acrylic acid amount on viscosity and polymerization yield. 
The increase of acrylic acid content generally has a positive influence on shrinkage. The value of polymerization yield stayed on the same level.

The effect of AIBN and acrylic acid amount on molecular mass of polymerized in extruder PSA was showed in Fig. 4.

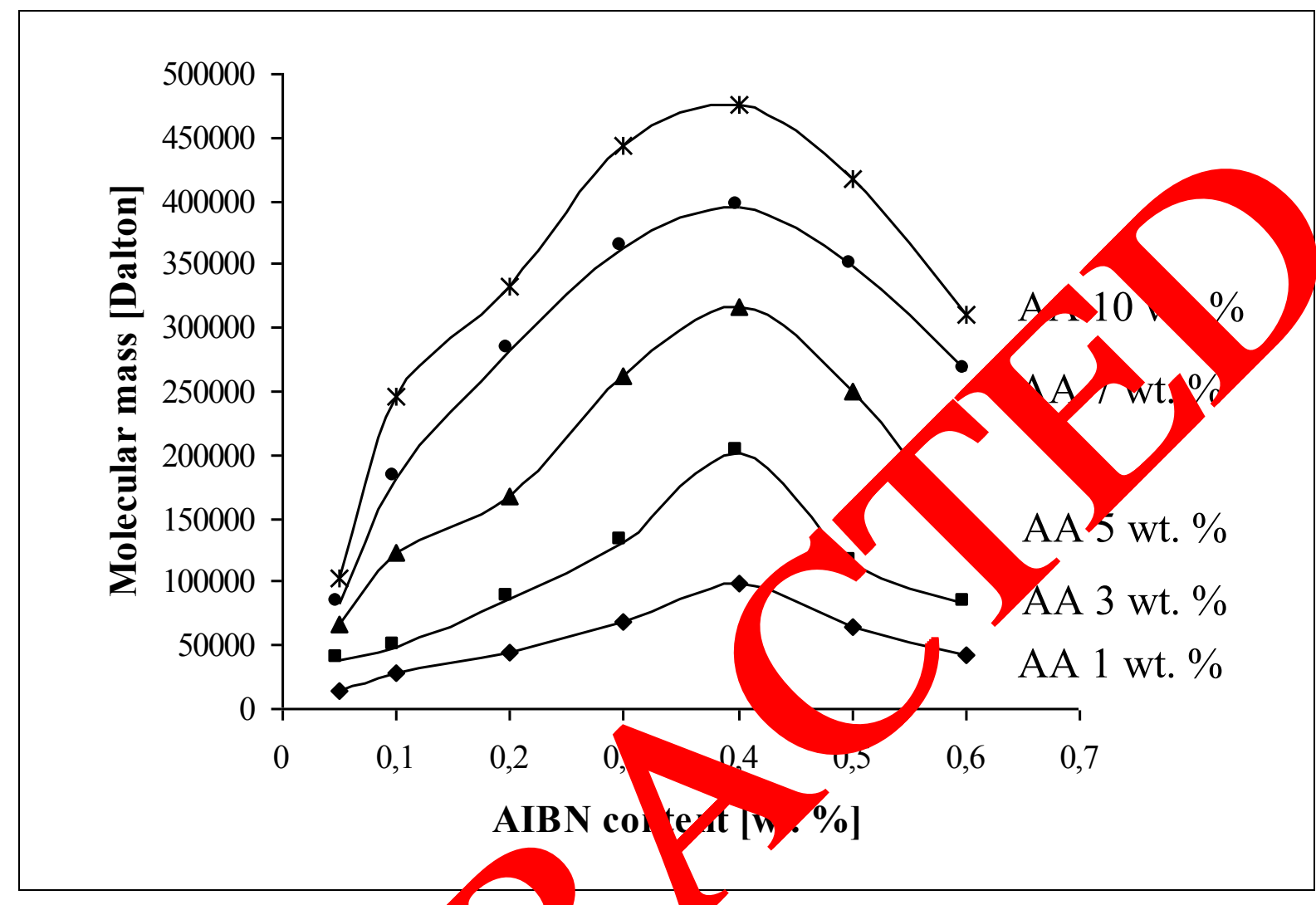

Fig. 4. Influence of AID $\mathrm{nd}$ ac slic acid oncentration on molecular mass of PSA.

The increase $a$ ac ic acid cy tent and increase of initiator AIBN content has a beneficial effect molec mass of synthesized PSA acrylics. The PSA with high molecular mase were polymen with 10 wt. \% of acrylic acid and about of $0.4 \mathrm{wt} \%$ of
AIBN.

\section{UV-cro king o tru er polymerizates}

As a suitable odel polymer the polymerizate has been selected with the highest nor lar $\left(M_{\mathrm{w}}=476000\right.$ Dalton) determined during the series of experiments. Althou. it was possible to crosslink this material $1000 \mu \mathrm{m}$ thick with UV radiation with UV lamp U 3. Y-I-DL from IST Company with UV-A wavelength between 315 do $400 \mathrm{~nm}$ and a constant $\mathrm{b} V$ dose of $800 \mathrm{~mJ} / \mathrm{cm}^{2}$ between $30 \mathrm{~s}$ and 3 minutes.

The result was far from being an acceptable coat of pressure-sensitive adhesive. The odour of residual monomers and the unacceptable ultimate elongation, which can be attributed to the embrittlement of the adhesive coat as a consequence of excessive UV curing, contributed to this.

The results of tested tack, adhesion and cohesion are presented in Figs. 5-6 


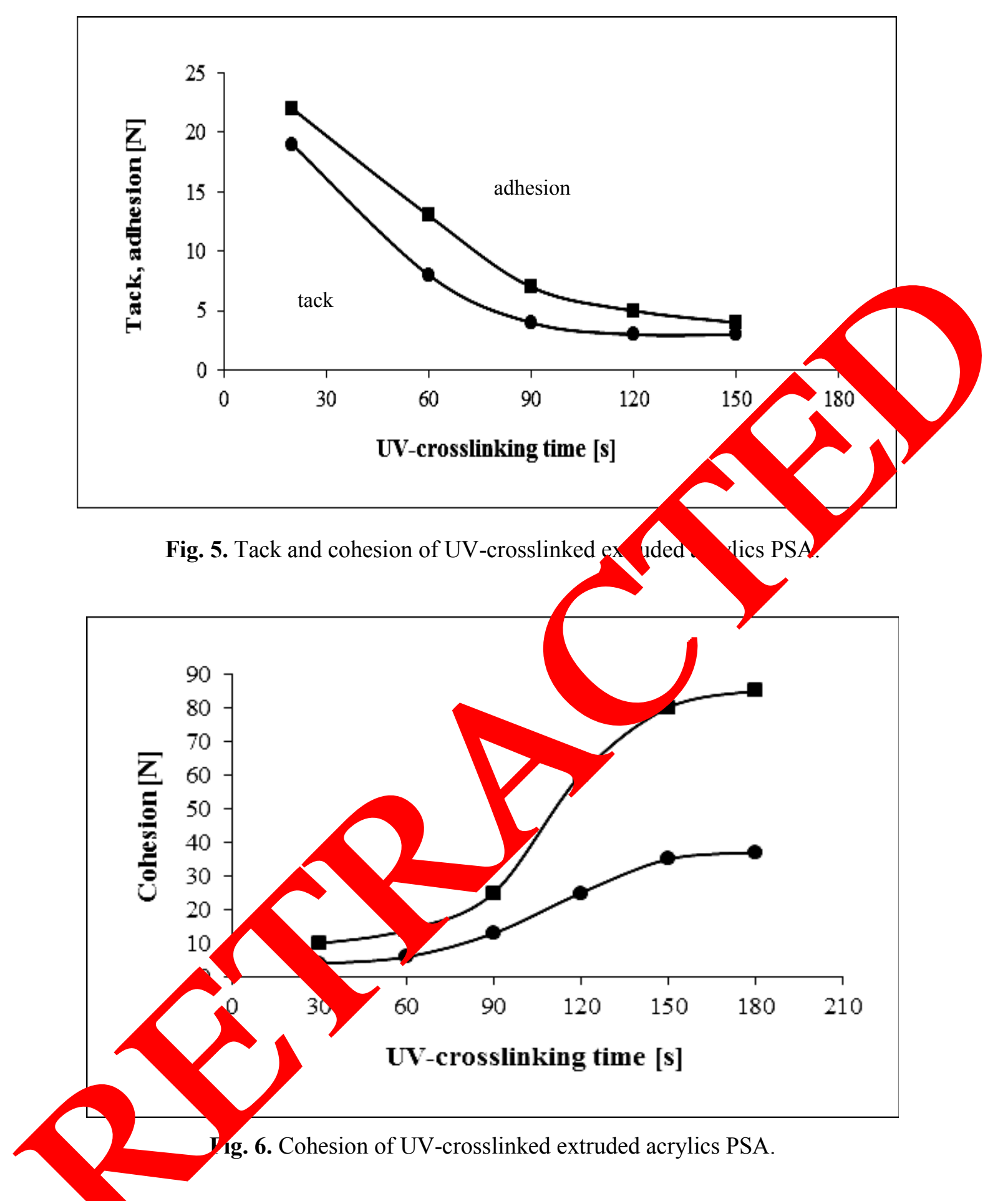

The osslinked PSA with high molecular mass and high viscosity gives the PSA the high level of cohesion performance after UV-crosslinking.

\section{Evaluation of the results}

We were not able to obtain a useable, polyacrylate-based pressure-sensitive adhesive by mass polymerization in the extruder, which would satisfy the normal requirements for a pressure-sensitive adhesive tape. The substantial drawbacks were as follows: 


\section{Gel particle content}

Because of the significant heat of the reaction in mass polymerization of the acrylate, it is almost impossible to adjust the temperature precisely, or at least this can only be done with difficulty, which leads to the formation of gels and products of degradation.

\section{Residual monomer content}

The holding time, expressed by the speed of the screw, in the extruder can only be adapted to the polymerization process with some difficulty. De facto this means too short a reaction space and hence an unacceptable reaction time. On the other hand, extending the extruder does not guarantee the secondary reaction and thus the reduction of the of residual monomer. The integrated degassing zone also ensures that removal $c$ the resic monomers is incomplete.

\section{2. Polymerization in the reactor with removal of the solvent}

Polymerization takes place in the organic solvent (e.g. nyl acet. petr 1, acetone, toluene), with a covalent photoinitiator being incorporate the polyn chain during polymerization. The polymerization medium is then reman uno vacuun. The resultant polymerizate is then, in a manner similar to a classica melt, co at high temperature and crosslinked in seconds or minutes with UV radi tion. This concep is based on tried and tested techniques and comes with the least risks. I wever, it is built on a pseudo-hot melt pressure-sensitive adhesive, since solvents are indee sed. The ignificant point is that there is the advantage that, by contrast to the mild, slow d. large quantities of solvent are rapidly dri $m$ the adhesive material, which can then processed like a hot melt. The solvent re noy a naturally, be used again for the polymerization process [13].

As a standard, a pressure sen ve adh ive acrylic has been polymerized with the following composition:

in ethyl acetate vith $50 \mathrm{wt}$ \% $\mathrm{p}$ mer content.

Once $e$ vl ace is removed, there remains a non-volatile, solvent- free highly viscous material, whic 1 be pro essed on a hot-melt coating machine at temperatures of between 100 and ${ }^{d-9}{ }^{\circ} \mathrm{C}$.

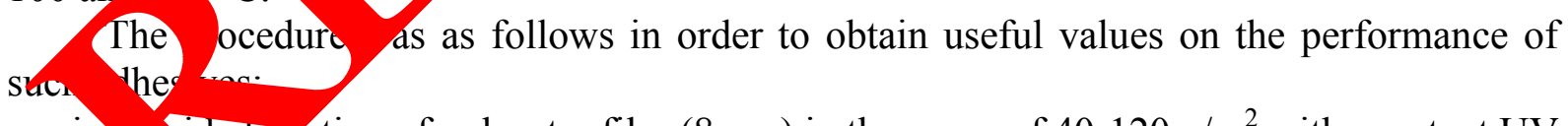

- sing vided coating of polyester film $(8 \mu \mathrm{m})$ in the range of $40-120 \mathrm{~g} / \mathrm{m}^{2}$ with constant UV radiati varying coating rates

- production of a typical double-sided adhesive tape (with paper substrate) for mediumweight use at varying coating rates and constant radiation dose.

Working conditions: Extruder

Wide slot nozzle

UV radiation lamp from IST Company 
An initial screening revealed that apart from the own polymerizate (HM1) and the hotmelt pressure-sensitive adhesives from a manufacturer of adhesive raw materials well-known in the market-place (HM 2) were worthy of further examination (Tab. 1).
Working process:
Wide slot nozzle
Backing:
12 pm PETP-fail
Liner:
Coat weight:
siliconized paper
Web speed:
$60 \mathrm{~g} / \mathrm{m}^{2}$
$5 \mathrm{~m} / \mathrm{min}$

Table 1. Comparision of various acrylate hot-melt pressure-sensitive adhesive

\begin{tabular}{|c|c|c|c|c|}
\hline \multirow{2}{*}{ Type } & \multirow{2}{*}{ Tack [N] } & \multicolumn{2}{|c|}{ Adhesion [N] } & \multicolumn{2}{c|}{ Cohesion [n } \\
\cline { 3 - 5 } & & $20{ }^{\circ} \mathrm{C}$ & $70{ }^{\circ} \mathrm{C}$ & $20{ }^{\circ} \mathrm{C}$ \\
& & & & \\
\hline HM 1 & 11.5 & 12.5 & 5.5 & \\
HM 2 & 12.0 & 11.5 & 5.0 & 60 \\
HM 3 & 6.0 & 8.0 & 4.0 & 0 \\
HM 4 & 3.5 & 7.0 & 30 & 10 \\
HM 5 & 2.0 & 7.0 & 2.0 & 7 \\
\hline
\end{tabular}

The limits of the bond-coat weights were det ined and the crosslinking rates using the own synthesized Products HM 1. These vere $60 \mathrm{~g} / \mathrm{h} \quad 20 \mathrm{~g} / \mathrm{m}^{2}$ and between 5 and 20 $\mathrm{m} / \mathrm{min}$ (Fig. 7). Adhesion at $20^{\circ} \mathrm{C}$ and coh $\quad-70^{\circ} \mathrm{C}$ for UV-crosslinked hot-melt PSA acrylics were tested.

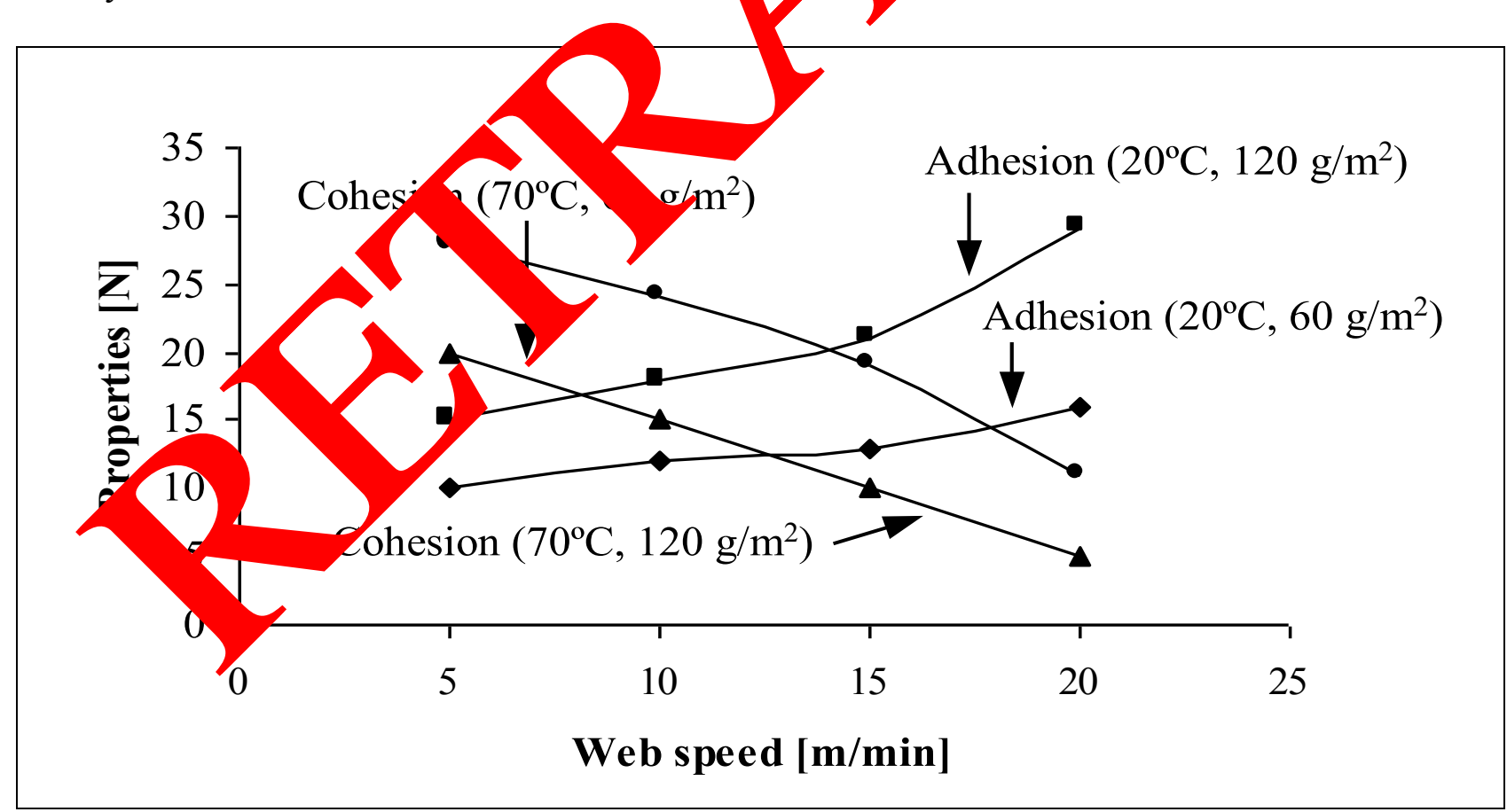

Fig. 7. Influence of web speed at $60 \mathrm{~g} / \mathrm{m}^{2}$ and $120 \mathrm{~g} / \mathrm{m}^{2}$ coat weight on adhesion and cohesion. 
It was determined that, within the various test groups (mass application/coating rate) the adhesive power at $20{ }^{\circ} \mathrm{C}$ with increasing coating rate and the cohesion decreases with increasing of web speed on the coating machine.

The performance at higher temperatures however showed typical weaknesses of a hotmelt. The UV-crosslinking was not able to make any improvement in this.

The adhesion properties of a double-sided adhesive tape, coated with a UV crosslinked acrylate hot-melt pressure-sensitive adhesive are respectable and encouraging by comparison with a conventional adhesive tape, as the Table 2 shows.

Table 2. Adhesion properties of UV-crosslinked hot-melt pressure-sensitive adhe

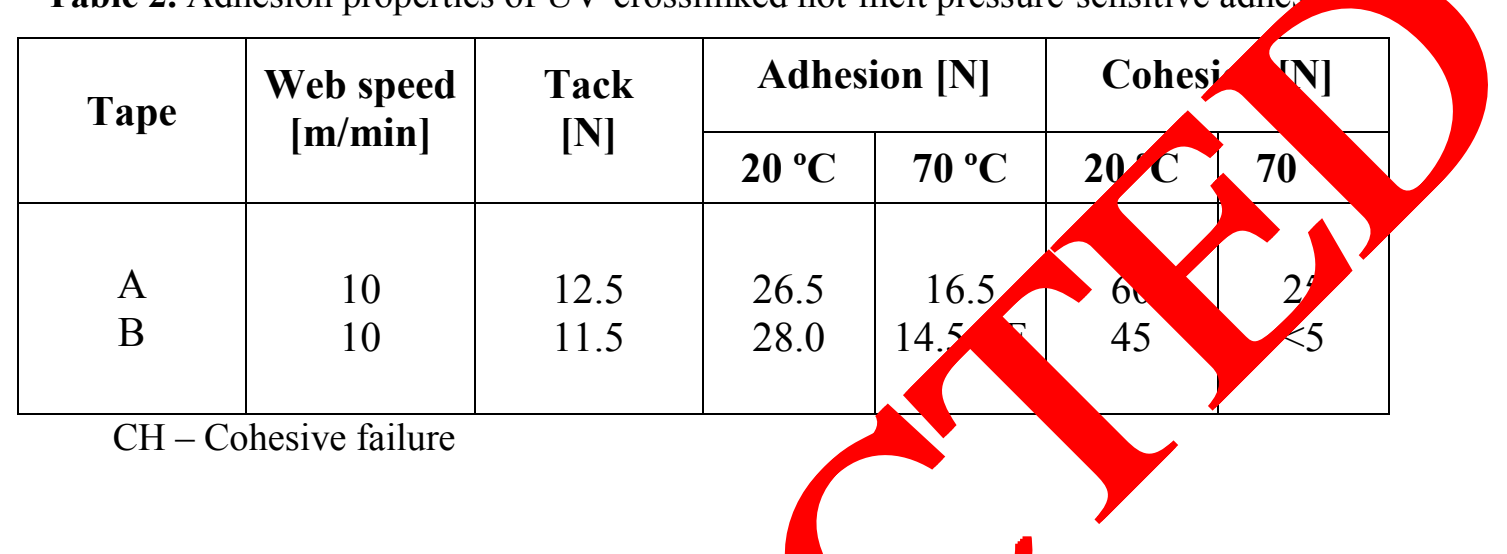

A Experimental product $2 \times 60 \mathrm{~g} / \mathrm{m}^{2} \mathrm{UV}$ crosslinked $12 \mathrm{~g} / \mathrm{m}^{2}$ paper substrate $90 \mathrm{~g} / \mathrm{m}^{2}$ silicon paper liner

B Standard adhesive tape $2 \times 60 \mathrm{~g} / \mathrm{m}^{2} \mathrm{UV}$ cross $^{1}$ ked $12 \mathrm{~g} / \mathrm{m}^{2}$ paper subs" $90 \mathrm{~g} / \mathrm{m}^{2}$ silicon aper liner

The UV-cross ked acrylies have very good tack, adhesion and cohesion at room and at higher tep peratures. Th and cohesive erforn nce. In th - case of PSA acrylic dispersions their performance at higher temperatures. op the ves small unacceptable level.

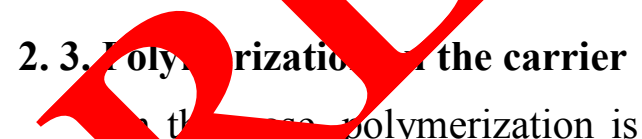
polymerization is shifted from the extruder to the substrate web, in that acrylat onomers recipe made as a coating compound are polymerized by UV radiation with the exclus of oxygen.

The $\mathrm{V} V$-polymerization and UV-crosslinking behavior will be treated from the change of the conversion ratio when photoinitiator is added to the syrup-PSA and actual UV radiation if performed and the molecular mass of the formed polymer.

Fig. 8 shows the relation between the UV energy with various irradiation strengths and the conversion ratio for a fixed addition amount of photoinitiator 4-acryloyloxy benzophenone (ABP). Here, the UV irradiation was performed with covering of the irradiation surface by a polyester foil separator to shut out oxygen. 


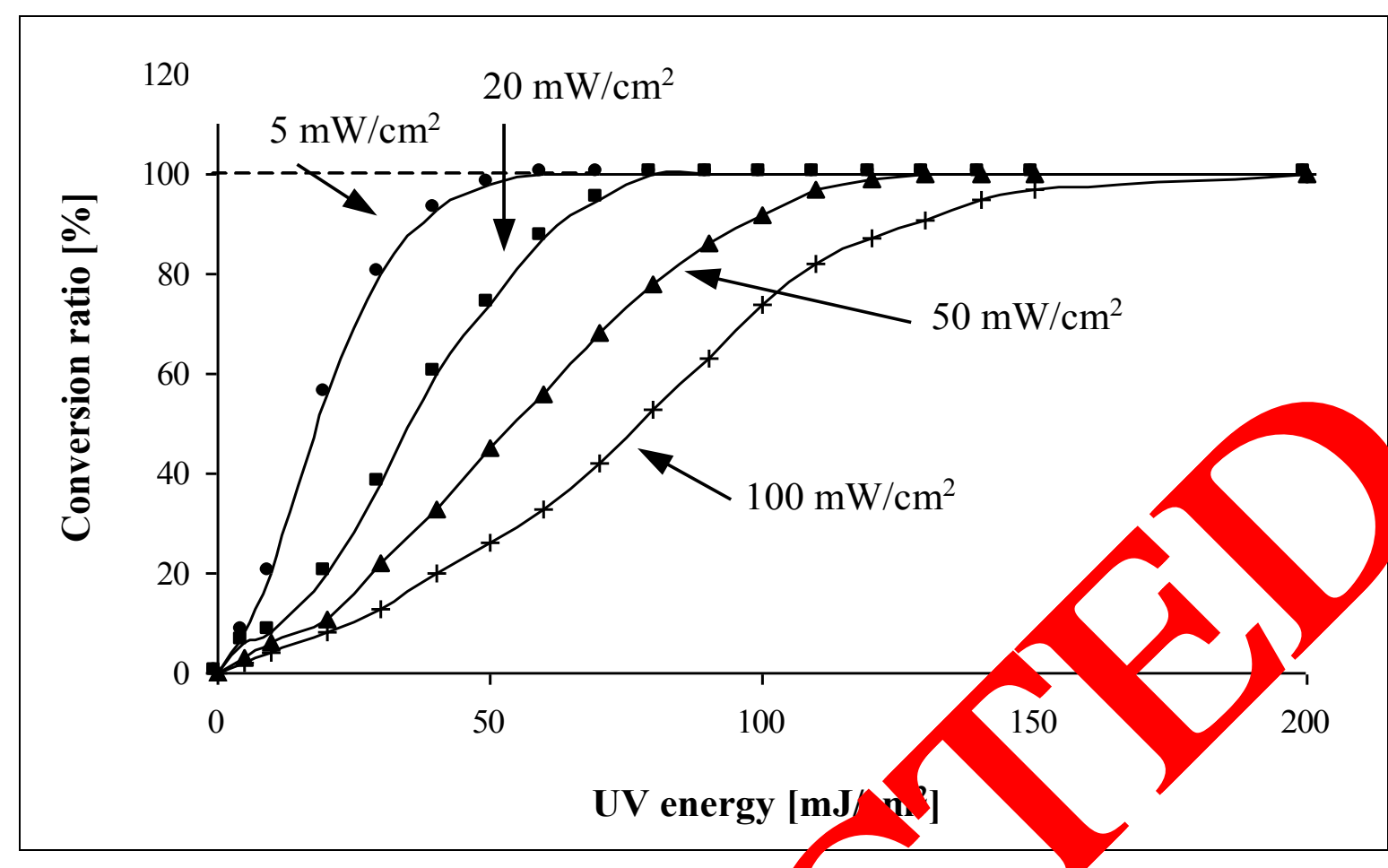

Fig. 8. Relation between the estimated UV lig amount and the conversion ratio.

The polymerization ratio in the UV-olymeriza

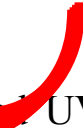
based on the general radical polymerization theory, and it in influenced widely by the amount of radicals generated per unit of tim alt, a high UV intensity is effective from the point of view of productivity as it re aces the time required for polymerization and photocrosslinking, but it means a lo ring of the adhesive performance, as the molecular mass of the formed polymers

Next, the crosslinkin oh a w w compared for the case when the UV irration surface is covered with polyester separator and when the UV irradiation atmosphere is changed to on oxy $\mathrm{n}$ entration of $5 \mathrm{wt}$. \% and $1 \mathrm{wt}$. \% respectively by nitrogen substitution. Fig. Shows th lation between the number of UV irradiation passes and the conversion ratic under the vario conditions.

With oxyg concentration of $5 \mathrm{wt} . \%$, the polymerization and photocrosslinking speed and the 1 cular $n$ ss of the formed polymer both drop widely in comparison to the method covo wiation a polyester foil, but with an oxygen concentration of $1 \mathrm{wt} \%$, the dror is sm and it an the range which can be realized. From this it can be said that at the timu ad manufacture it is required to either to cover the UV irradiation surface with a vester Ioil separator or similar or to perform UV irradiation in an atmosphere with an oxyge acentration of $1 \%$ or less by substitution of nitrogen or similar.

With a approximately one to two minutes (approximately $1000 \mathrm{~g} / \mathrm{m}^{2}$ coat weight) under these conditions, polymerization is complete, the end stage of which being characterized by a molecular mass such as we are familiar with from solvent polymerization. This is the decisive physical and chemical advantage of this method that does not depend on the molecular mass of the pressure-sensitive adhesive with respect to the process technology. 


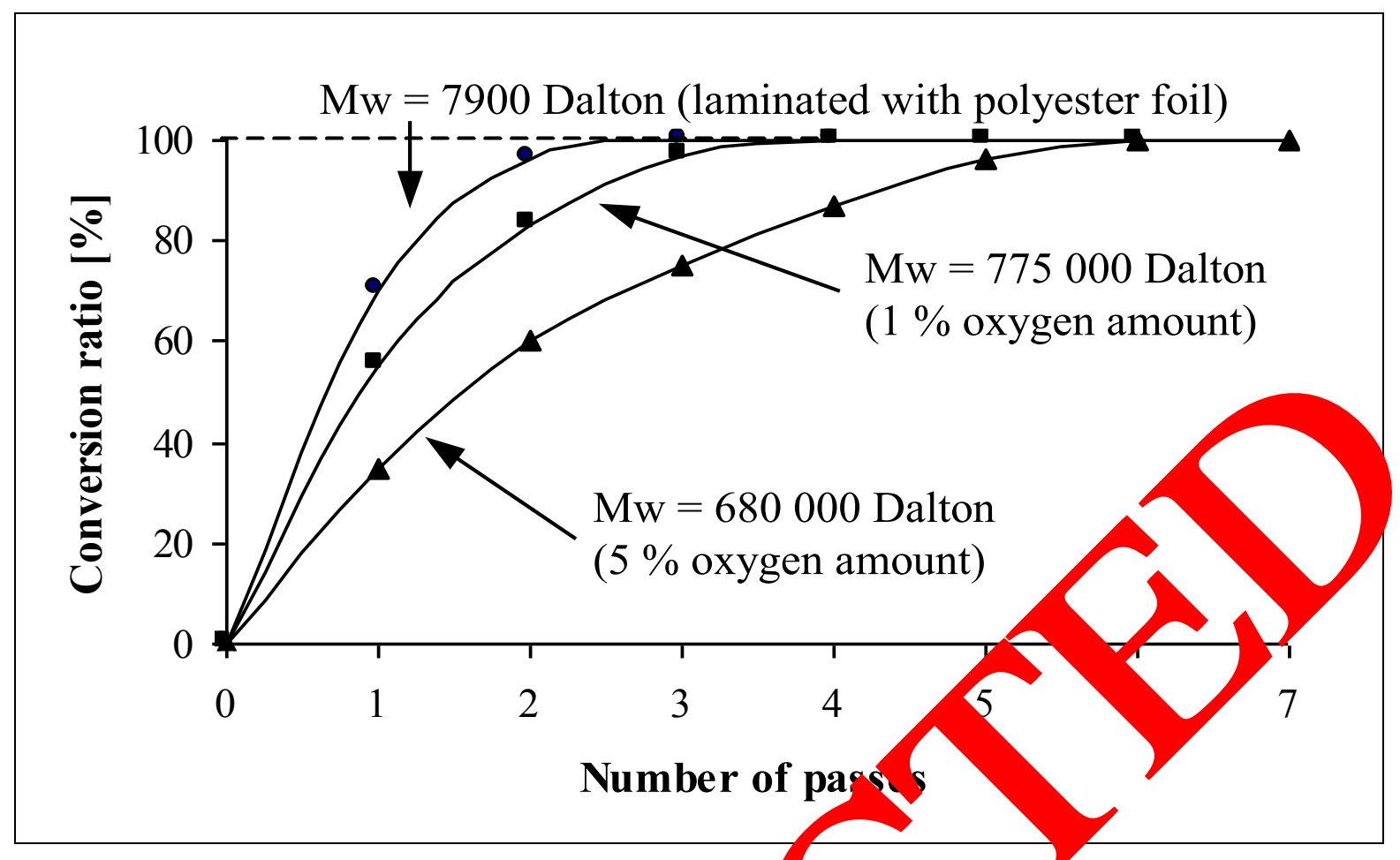

Fig. 9. Influence of the oxygen amount or 0 the crosslinking behaviour.

Complete freedom from solvents, a further pl. oint, is however, counteracted by a relatively high residual monomer content an block corvmeng that can only be achieved to a limited extent, indispensable for same applic tio. takes only seconds, UV polymerization takes 0 two ninutes, but at least ten times as long? On the other hand, UV polymerizo is more $r$ less independent of the coating thickness of the PSA which means that it is stine above a Yor thick coats.

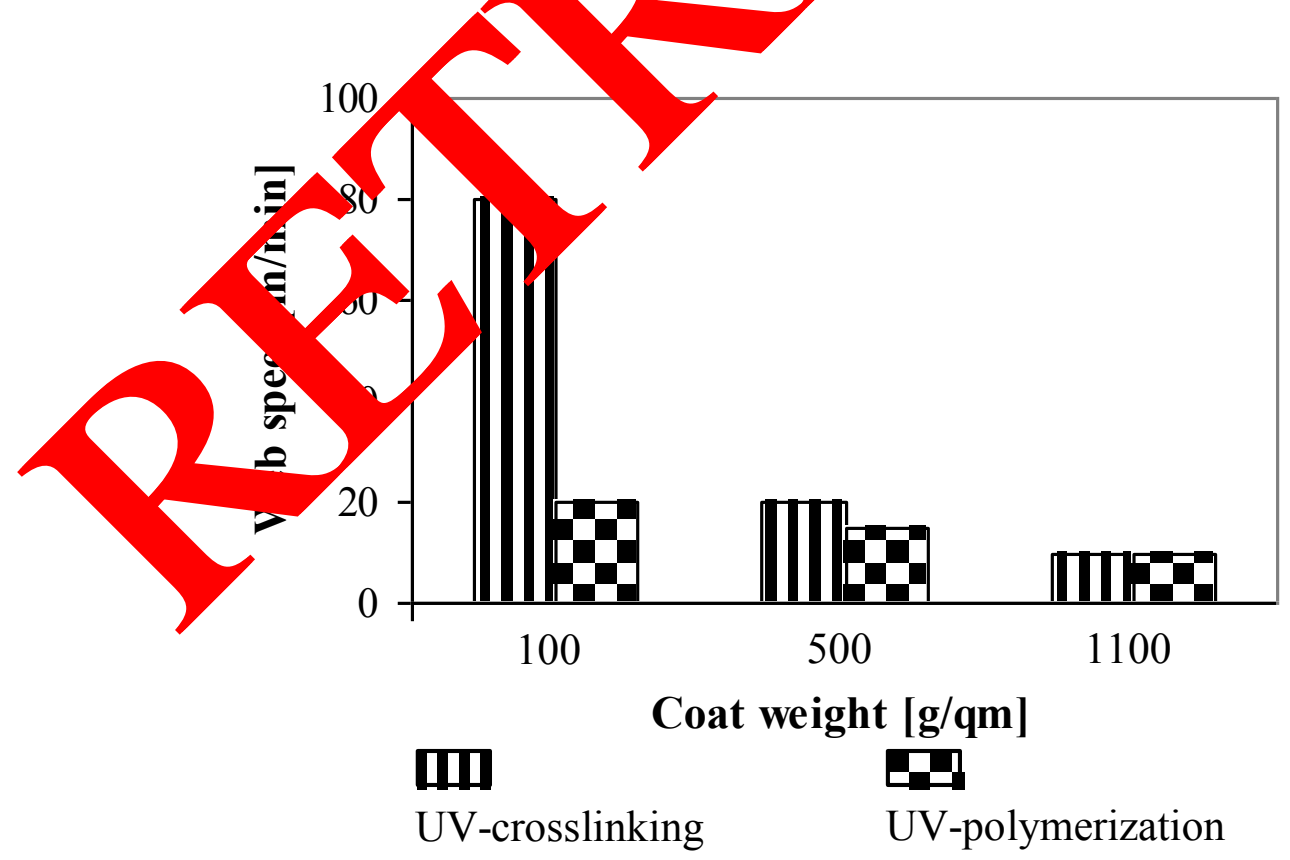

Fig. 10. Web speed vs. coat weight. 
The coating costs are derived from the costs per operating hour. A coating rate of 10 $\mathrm{m} / \mathrm{min}$ can still be assumed up to $1200 \mathrm{~g} / \mathrm{m}^{2}$; fewer than $150 \mathrm{~g} / \mathrm{m}^{2}$, the coating rate for UV curing is restricted to $80 \mathrm{~m} / \mathrm{min}$. In the case of UV polymerization, the dependence of the coating rate on the coat weight is, as anticipated, considerably less marked, as is shown by the bar chart below (Fig. 10).

The coating costs can be derived from this (Fig. 11).

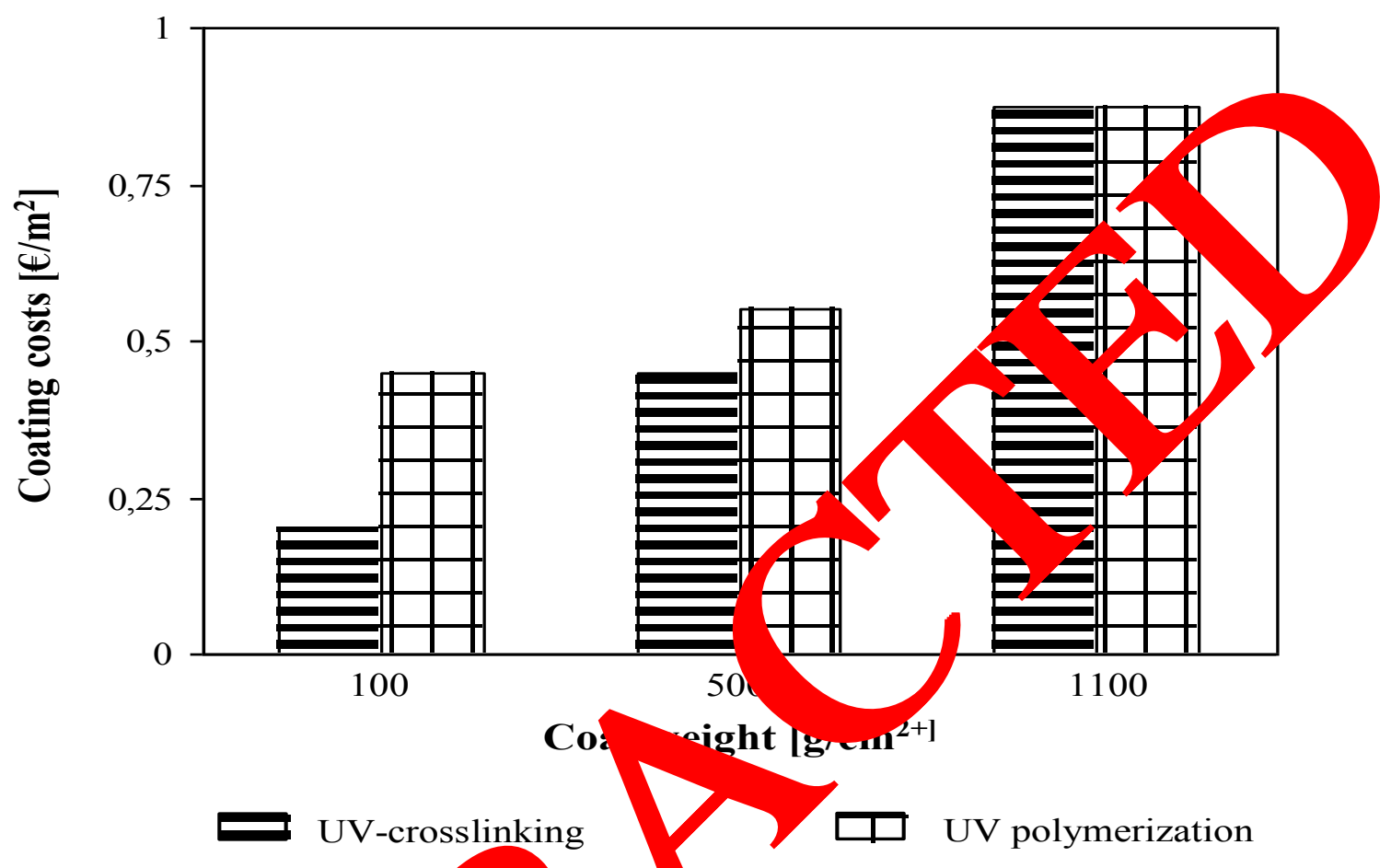

\section{CONCLUSION}

Fig. 11. $C$ ating sts as a fi ction of coating weight.

There ar num rous exam es of competing systems in nature not necessarily implying the extincti fo candle, for instance, still retains its niche despite the invention of th ectric alb. Producers of adhesive tape are also subject to the second princi therm nics, the law of entropy, and other laws of Nature. And they will mo fy the initially o promising, progress of new raw materials or innovative methods to a mars 1 ent, or sometimes no improvement at all.

u rosslinkable acrylic adhesives are certainly an alternative worth considering for companies fing no machinery of their own for coating adhesives containing solvents. They would be up-to-date, almost by the back door route, with pseudo- solvent acrylate pressuresensitive adhesives, as long as the chemistry is correct.

UV polymerized, thick acrylic hot-melt pressure-sensitive adhesive coatings created on the substrate are generating excitement about their properties, the only problem being that the market for them is characterized by a high barrier to entry. In addition, the company would be looking at a risky and expensive development, including a production plant which is yet to be designed. Small and medium sized adhesive tape companies will be overstretched by this. 
One unrestrictedly positive aspect is that solvent-free acrylic adhesives are not only in harmony with the increasing concerns for the environments, but the even make a decisive contribution to reducing the strain on the environment because of their omission or almost one hundred percent re-use of solvents.

\section{References}

[1] I. Benedeck, L. J. Heymans., Pressure-sensitive adhesives technology, New York: Marcel Deckker Inc., 1997.

[2] Z. Czech, Crosslinking of acrylic pressure-sensitive adhesives, Szczeci Politechn. Szczecinska, 1999.

[3] R. Milker Z. Czech, A. Butwin, U. Głuch, E. Madejska, Coating 3

[4] M. Dupont, C. Mayenez, Adhäsion 3 (1989) 22-27.

[5] K. H. Schumacher, U. Düsterwald, B. Mayer-Roscher, Veredelungsseminar, München, Oktober (1998) 112-11

[6] Z. Czech, A. Kowalczyk, J. Kabatc, J. Świderska, 1446-1454.

[7] Z. Czech, A. Kowalczyk, K. Górka, U. Głuc L. Shao, Iolish Journal of Chemical Technology 14(3) (2012) 83-87.

[8] Z. Czech, F. Herrmann, Patent DE 42 re (1992) Lurnnann GmbH \& Co. KG.

[9] Z. Czech, Patent DE 19501025 (1995) L hm MbH \& Co. KG.

[10] Z. Czech, W. Blum, Patent D 06 97入 1994) Lohmann GmbH \& Co. KG.

[11] N. Matsuoka, H. Matsur Pa nt DE 3305727 (1983) Nitto Eletric Industrial.

[12] S. Plamthottam, E. Y.ArcFo rs, US T atent 5, 100,728 (1990) Avery Dennison Corporation.

[13] Z. Czech, Kaum shuk rmi Kunststoffe 10 (2002) 492-501.

[14] Zbigniew Czech Agnieszı Kowalczyk, Dominika Sowa, International Letters of Chemi Phy and Astronomy 1 (2013) 63-69.

[15] Zbioniew ch, Do rinika Sowa, Jagoda Kowalska, International Letters of

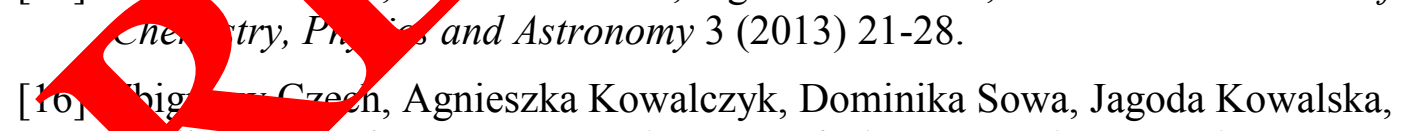
ina Ragańska, International Letters of Chemistry, Physics and Astronomy 8(1) (20) 19 -56.

[17] Zbigniew Czech, Dominika Sowa, Jagoda Kowalska, Paulina Ragańska, International Letters of Chemistry, Physics and Astronomy 8(1) (2013) 57-65. 